\title{
Escola Profissionalizante e o método de ensino e aprendizagem na Educação Física
}

\author{
José Demontier Guedes ${ }^{1}$; Cassiano Cezar Ferreira Duarte²; Joyce Gonçalves Feitosa3; \\ Leonardo Gonçalves Feitosa dos Santos ${ }^{4}$; Pedro Anderson Barbosa da Silva \\ Antonio Júlio César Almeida de sousa ${ }^{6}$; Torben Alencar Vieira ${ }^{7}$
}

\begin{abstract}
Resumo: O objetivo geral do presente estudo é compreender a importância do ensino, aprendizagem e seus métodos utilizados para a pratica da Educação Física, e principalmente, como ela é aplicada na na escola profissionalizante. Quanto aos objetivos específicos, investiga-se a importância do ensino e aprendizagem quanto a estimular os alunos na prática de atividades corporais, buscando compreender o método aplicado em sala de aula pelo professor de educação física e, o consequente desenvolvimento dos alunos. Utlilizou-se um questionário qualitativo, o qual foi respondido por uma profissional de Educação Física do colégio profissionalizante E.E.M.P Governador Virgílio Távora. Os resultados demonstraram que a falta de espaço tem sido um problema, dificultando as aulas e uma metodologia mais interativa com movimentos, implicando em que o professor tenha que improvisar no decorrer das aulas. O método de ensino é desenvolvido pela professora, a qual organiza as atividades de ensino e dos alunos para atingir objetivos de trabalho docente em relação à aprendizagem e o ensino, tem como finalidade a compreensão das aulas de educação física em escolas profissionalizantes.
\end{abstract}

Palavras-chave: Educação Física. Ensino. Aprendizagem

\section{Vocational School and the method of teaching and learning in Physical Education}

\begin{abstract}
The overall objective of this study is to understand the importance of teaching, learning and methods used for the practice of physical education, especially as it is applied in the vocational school. Regarding the specific objectives, the importance of teaching and learning is stimulated in order to stimulate the students in the practice of body activities, seeking to understand the method applied in the classroom by the physical education teacher and the consequent development of the students. A qualitative questionnaire was used, which was answered by a Physical Education professional from the vocational college E.E.M.P Governador Virgílio Távora. The results showed that lack of space has been a problem, making classes more difficult and a more interactive methodology with movements, implying that the teacher has to improvise during the lessons. The teaching method is developed by the teacher, who organizes the teaching activities and the students to achieve objectives of teaching work in relation to learning and teaching, has the purpose of understanding the physical education classes in vocational schools.
\end{abstract}

Keywords: Physical Education. Teaching. Learning

\footnotetext{
${ }^{1}$ Orientador. Docente do Curso de Educação Física do instituo Dom josé. Mestre em ciências da Educação. Especialista em Português e ArteEducação. Psicólogo. Pedagogo. Email: proerddemontierguedes@ gmail.com.

${ }^{2}$ Graduando em Licenciatura Plena em Educação Física, na Universidade Vale do Acaraú, Instituto Dom José Educação e cultura - UVA- IDJ, no Municipio do Crato, Ce. Email: Cassiano-cezar@bol.com.br.

${ }^{3}$ Graduanda em Licenciatura Plena em Educação Física, na Universidade Vale do Acaraú, Instituto Dom José Educação e cultura - UVA- IDJ, no Municipio do Crato, Ce. Email: Joyce.g.feitosa2206@gmail.com.

${ }^{4}$ Graduando em Licenciatura Plena em Educação Física, na Universidade Vale do Acaraú, Instituto Dom José Educação e cultura - UVA- IDJ, no Municipio do Crato, Ce. Email: leofeitosa96@yahoo.com.br.

${ }^{5}$ Graduando em Licenciatura Plena em Educação Física, na Universidade Vale do Acaraú, Instituto Dom José Educação e cultura - UVA- IDJ, no Municipio do Crato, Ce. Email: Pedroderson93@gmail.com.

${ }^{6}$ Graduando em Licenciatura Plena em Educação Física, na Universidade Vale do Acaraú, Instituto Dom José Educação e cultura - UVA- IDJ, no Municipio do Crato, Ce. Email: Antoniojuliocesar@hotmail.com.

${ }^{7}$ Graduando em Licenciatura Plena em Educação Física, na Universidade Vale do Acaraú, Instituto Dom José Educação e cultura - UVAIDJ, no Municipio do Crato, Ce. Email: Torben_alencar@hotmail.com.
} 
Id on Line Revista Multidisciplinar e de Psicologia

Id on Line Multidisciplinary and Psycology Journal

\section{Introdução}

O Aprendizado não se resume apenas em entender algum conteúdo, e sim compreender e saber utiliza-lo no cotidiano, é saber repassar o que foi aprendido e sair do ato de "decorar". Quando a relação aluno e professor se torna equilibrada, o ato de aprendizado se torna mais fácil, pois essa relação acaba trazendo um bem-estar individual e social para cada indivíduo dentro do âmbito escolar.

[...] quando um professor pensa que ensino e aprendizagem são duas faces de um mesmo processo, faz sentido acreditar que, ao final dele, só existam duas alternativas: o aluno aprendeu, ou não aprendeu. (WEISZ, 2006),

A questão do aprender difere da forma que lhe é apresentada. O professor irá ser um importante mediador do conhecimento, pois, ao propor algo, terá sempre que facilitar, respeitando o limite de cada aluno, fazendo assim com que eles assimilem, interpretem e consigam colocar em pratica o que foi interposto pelo professor. Também, se deve considerar o interesse e capacidade de assimilação do aluno, os quais, poderão influenciar diretamente na questão "o aluno aprendeu, ou não aprendeu"

Brito (1999) aponta que:

[...] a falta de contextualização dos conteúdos das aulas, já que 74,4\% dos alunos de um Colégio afirmaram que nas aulas "práticas" não existem explicações teóricas do conteúdo ministrado. Desta forma, a aula de Educação Física perde o seu significado, caracterizando-a cada vez mais como uma atividade.

O professor de educação física deverá ter a metodologia do ensino bem planejada, colocando em questão a relação Prática e Teoria, pois, isso contribui para uma melhor aprendizagem, havendo um aproveitamento mais significativo das aulas, assim o aluno passa a compreender mais o que está sendo transmitido pelo Professor que é o mediador entre o conhecimento e o aluno, sendo que a teoria é um fator fundamental para essa relação, fazendo com que o aluno passe a entender de uma forma mais aberta. Segundo Moura \& Araújo \& Moretti \& Panossian \& Ribeiro apud Moretti (2007, p. 101):

[...] oscilando entre momentos de reflexão teórica e ação prática e complementandoos simultaneamente que o professor vai se constituindo como profissional por meio de seu trabalho docente, ou seja, da práxis pedagógica. Podemos dizer então que: se, dentro da perspectiva históricocultural, o homem se constitui pelo trabalho, entendendo este como uma atividade humana adequada a um fim e orientada por 
objetivos, então o professor constitui-se professor pelo seu trabalho - a atividade de ensino - ou seja, o professor constitui-se professor na atividade de ensino. Em particular, ao objetivar a sua necessidade de ensinar e, conseqüentemente, de organizar o ensino para favorecer a aprendizagem

Ao se tornar professor, o indivíduo passa a ser um facilitador de conhecimento, logo, é necessário que o mesmo planeje e construa suas metas de acordo com os educandos e com o ambiente onde irá desenvolver toda a disciplina quanto a teoria e prática também o facilitador é primordial neste processo de junção da prática e teoria, atravlés dele e assim tendo um ambiente e vestes adequadas somando com a mediação dos conhecimentos desenvolvidos em sala e em quadra torna o caminho em relação ao ensino com melhor aproveitamento.

[...] para descobrir o que no desenvolvimento do conhecimento beneficia o desenvolvimento psíquico, é necessário conhecer como é assimilado o material escolar, ou seja, que operações de pensamento se usam. (MOURA \& ARAÚJO, et tal. 2003, p. 48).

\section{Educação Física no ensino Profissionalizante}

Mediante a pesquisa qualitativa realizada no colégio Virgílio Távora pode-se observar que a professora considera importante desenvolver o trabalho unindo a teoria e a prática, para assim facilitar à compreensão dos alunos em relação aos conteúdos que foram abordados nas aulas de Educação Física. Tendo em vista que é uma escola profissionalizante as aulas não são no contra turno, fazendo assim parte da grade curricular. Porém a estrutura disponibilizada para as aulas referentes a disciplina não se pode desenvolver pois iniciou-se uma obra e há três anos e não foi concluída, devido a isto o professor usa de adaptações no espaço inadequado de se acontecer as atividades curriculares para assim realizar jogos prédesportivos, populares, de tabuleiro, lúdicos e outras atividades menos o esporte em si, por conta da impossibilidade de usufruir da quadra mesmo com a cobrança dos alunos. Com base nisto

Os espaços educativos, como lugares que abrigam a liturgia acadêmica, estão dotados de significados e transmitem uma importante quantidade de estímulos, conteúdos e valores (...), ao mesmo tempo em que impõem suas leis como organizações disciplinares. (MATOS apud ESCOLANO, 1998, p.27) 
Id on Line Revista Multidisciplinar e de Psicologia

Id on Line Multidisciplinary and Psycology Journal

O espaço escolar é de grande importância para os alunos, pois é nele que se desenvolve a aprendizagem tanto na teoria quanto o que vai ser aplicado a pratica, não deixando de lado a junção de ambas que também é fundamental para o conhecimento dos mesmos. Levando em consideração que não se pode deixar de realizar aulas práticas por falta da quadra, sendo assim o professor deve saber adaptar as atividades que o mesmo planejou para um bom andamento da aula e não deixar que os alunos sejam prejudicados por falta de um ambiente adequado.

Em relação ao material esportivo há um bom estoque em equipamentos para a utilização nas aulas práticas de Educação Física e assim supri as necessidades do colégio com relação à prática. O colégio também disponibiliza a vestimenta para que possam participar das aulas físicas, sem que haja algum desconforto ou que aconteça alguma eventualidade com os discentes por estarem vestidos de forma inadequada. Sendo que é propiciado aos alunos um vasto aparato teórico e prático fornecido pela professora, tendo isto em vista observa-se à assimilação dos alunos quanto ao conteúdo expandindo o conhecimento dos mesmos. O ambiente para a realização das aulas de educação física é de extrema importância e de acordo com Matos apud Escolano (2001, p.45) “A arquitetura escolar pode ser vista como um programa educador, ou seja, como um elemento do currículo invisível ou silencioso, ainda que ela seja, por si mesma, bem explícita ou manifesta."

A grade curricular da escola profissionalizante tem como prioridade o ENEM, deixando um pouco de lado o incentivo esportivo como participações em jogos escolares, porém existe o costume de realizar os jogos interclasses, afirmou-se que os jovens estudantes são motivados a uma vida saudável nas aulas de Educação Física. Mas por ser um colégio profissionalizante existem cursos ofertados como Enfermagem, Informática e Regência, entretanto as aulas são diferenciadas para os educandos de enfermagem acrescenta-se para a saúde quanto lesões esportivas, já Informática e Regência não tem esse enfoque, ficam mais voltados ao esporte. A professora responsável nos afirmou que considera muito importante que os alunos tenham consciência da importância da atividade física para a vida deles, para que fiquem bem quanto a sua saúde corpórea e uma boa qualidade de vida. 
Id on Line Revista Multidisciplinar e de Psicologia

Id on Line Multidisciplinary and Psycology Journal

\section{A importância da capacitação do professor de Educação Física.}

Segundo Chimentão (2009, p. 3)

A formação continuada de professores tem sido entendida como um processo permanente de aperfeiçoamento dos saberes necessários à atividade profissional, realizado após a formação inicial, com o objetivo de assegurar um ensino de melhor qualidade aos educandos.

Para garantir uma melhor qualidade de ensino o professor tende a seguir estudando e qualificando-se mais por meio de pós-graduações, mestrados, doutorados etc. Mediante a esta situação pode-se verificar que a educadora avaliada por esta pesquisa buscou aumentar seu conhecimento para atender melhor às necessidades dos indivíduos esta é graduada pela UNIVERSIDADE REGIONAL DO CARIRI (URCA), ESPCIALISTA EM EXERCICIO FÍSICO COM REABILITAÇÃO CARDIACA EM GRUPOS ESPECIAIS. Tem como mecanismo de avalição provas mensais e bimestrais escritas e práticas. Para Mileo e Kogut (2009, p. 4 47- 4948),

Cabe ao professor manter-se qualificado para que possa atender as necessidades de seus alunos bem como da sociedade. Uma vez que, o mercado de trabalho busca o profissional melhor qualificado, flexível e disposto para enfrentar os desafios a ele proposto, visando uma melhoria na educação e no ensino. Portanto, apenas a formação inicial não é suficiente para a garantia da qualificação dos professores na atualidade.

\section{Metodologia}

O estudo foi desenvolvido através de pesquisa em campo, no E.E.M.P. Virgílio Távora, onde foi realizada uma entrevista com a professora de educação física no período da tarde, foi elaborado um questionário para a entrevistada realizando uma observação do ambiente. Junto à pesquisa de campo, buscamos fontes diretamente na internet, citações em livros e artigos acadêmicos. Seguimos a linha de pensamento de autores, Weisz, Brito, Matos, Escolano entre outros. 
Id on Line Revista Multidisciplinar e de Psicologia

Id on Line Multidisciplinary and Psycology Journal

\section{Resultados e Discussão}

Mediante a pesquisa de campo pode-se observar o método de trabalho da professora na escola profissionalizante Virgílio Távora nas aulas de Educação Física, no qual articulou que a sua tática de ensino é idealizada em aulas teóricas e práticas em que os conteúdos são divididos por bimestre, onde aborda diversos temas durante o ano letivo, dentre eles os jogos populares, jogos de tabuleiro, atividades rítmicas, esporte entre outros.

No decorrer da entrevista, a professora relata a falta da quadra esportiva que é utilizada para a execução das aulas práticas, mas faz três anos que está em reforma, tendo que improvisar no espaço da escola para que os alunos possam ter o ensino e aprendizagem dos conteúdos. Diante desta circunstância entra se em questão a importância de um espaço para a excursão das aulas práticas de educação físicas por, mas que tenham uma aula teórica bem aplicada a falta da quadra limita o fator de assimilação dos alunos.

Durante as aulas de educação física, a pratica entra como um complemento da teoria, os alunos executam o que aprendem em sala e desenvolvem melhor as tarefas propostas, sendo assim primordial o uso da quadra principalmente em atividades esportivas que trabalha os fundamentos dos esportes, táticas de jogo dentre outros. Também é colocado o uso do material didático, onde somente a professora tem acesso a apostila que serve como um dos seus instrumentos de ensino, e similarmente com o autor narras, com o livro saúde, qualidade de vida, conceitos e interversões, onde sempre expõe em suas aulas. Ao contrário da quadra que não se tem acesso, a professora cita que não falta o material esportivo, que é usado nas aulas práticas, "Material a gente tem, mas a quadra ainda está inutilizada".

\section{Considerações Finais}

$\mathrm{Na}$ escola profissionalizante, além de mediado os conhecimentos para o educando, procura-se também promover o aumento na qualidade de vida por meio da socialização, atividades físicas, motivação para cuidar da saúde. Assim pode-se perceber que o ensino e a aprendizagem tem sido o foco dos educadores os quais apesar de tantas dificuldades insistem em variar suas aulas e adaptarem-se ao ambiente para melhor atender as necessidades dos 
alunos, não é uma quadra estabilizada em uma reforma de três longos anos que irá impedir que seja facilitado o conhecimento para o aluno, nem tão pouco deixar de promover saúde, bemestar físico e mental para os alunos desta instituição profissionalizante gerando também qualidade de vida e aprendizagem para os mesmos.

Conclui-se que, apesar das dificuldades encontradas no local da pesquisa não há interferência no ensino e aprendizagem por conta de que os alunos estão conscientes da importância das aulas desenvolvidas e os educadores estão sempre os motivando e esclarecendo-os da importância que tem a aula de Educação Física, as atividades corporais com finalidade a manutenção da saúde para assim terem uma vida com qualidade.

\section{Referências}

CHIMENTÃO, Lilian Kemmer. Significado da formação continuada docente. Artigo 2009. Disponível em: http://docplayer.com.br/321442.

MOURA, ARAÚJO, MORETTI, PANOSSIAN e RIBEIRO apud BOGOYAVLENSKY e MENCHISKAYA. Atividade orientadora de ensino: unidade entre ensino e aprendizagem. Revista Diálogo Educacional, v.10, n.29, 2010.

OLIVEIRA, Amauri Aparecido Bassoli. Metodologias emergentes no ensino da educação física. In Conexões: Revistada Educação Física/UEM, v. 8, n. 1, 1997.

LORENZ, Camila F; TIBEAU, Cynthia. Educação Física no ensino médio: estudo exploratório sobre os conteúdos teóricos. Revista digital, v. 9, n. 66, novembro de 2003.

MATOS, Marcelo da cunha. Espaço Físico Escolar: Objeto indispensável para Educação Física? Disponível em: http://cev.org.br/biblioteca/espaco-fisico-escolar-objeto-indispensavelpara-educacao-fisical. 1998.

\section{Como citar este artigo (Formato ABNT):}

GUEDES, J.D.; DUARTE, C.F.; FEITOSA, J.G.; SANTOS, L.G.F.; SILVA, P.A.B.; SOUZA, A.J.A.; VIEIRA, T.A. Educação Escola Profissionalizante e o método de ensino e aprendizagem na Educação Física. Id on Line Revista Multidisciplinar e de Psicologia, Janeiro de 2017, vol.10, n.33, Supl 2. p. 87-93. ISSN: 1981-1179. 